\title{
Household energy consumption pattern changes in an aging society: the case of Japan between 1989 and 2014 in retrospect
}

\author{
Nozomu Inoue $^{1} \cdot$ Shigeru Matsumoto ${ }^{2}$ (D) Kozo Mayumi ${ }^{3}$
}

Received: 18 August 2021 / Accepted: 26 September 2021 / Published online: 21 October 2021

(c) Japan Economic Policy Association (JEPA) 2021

\begin{abstract}
This study examines how population aging affects household energy consumption, first presenting a theoretical framework to assess three effects of population aging on household energy consumption: the pure aging effect, the cohort effect, and the family structure effect. An empirical model is constructed to investigate these three effects based on Japanese households' micro-level energy consumption data from 1989 to 2014. Elderly people tend to secure physical comfort at home in summer and winter, resulting in increased energy consumption, known as the pure aging effect. Our analysis of this effect indicates that household energy consumption increased by about $12 \%$ from 1995 to 2015 . The diverse energy use patterns of different generations associated with lifestyle preferences are referred to as the cohort effect. A less intensive energy consumption pattern is identified for cohorts of younger generations, confirming our hypothesis. Although economies of scale in household energy consumption are present, the size of Japanese households has decreased in the last several decades, which is called the family structure effect. The family structure effect is also confirmed. Household energy consumption increased by about $16.6 \%$ from 1990 to 2015 . These results strongly suggest a substantial impact of population aging on household energy consumption in the case of Japan.
\end{abstract}

Shigeru Matsumoto

shmatsumoto@aoyamagakuin.jp

Nozomu Inoue

econinoue@ipss.go.jp

Kozo Mayumi

k_mayumi@kcg.ac.jp

1 Department of Theoretical Social Security Research, National Institute of Population and Social Security Research, Hibiya Kokusai Building 6th Floor, 2-2-3, Uchisaiwai-cho, Chiyoda-ku, Tokyo 100-0011, Japan

2 Department of Economics, Aoyama Gakuin University, Room 828, Building 8, 4-4-25 Shibuya, Shibuya, Tokyo 150-8366, Japan

3 The Kyoto College of Graduate Studies for Informatics, 7 Tanakamonzen-cho, Sakyo-ku, Kyoto 606-8225, Japan 
Keywords Household energy consumption $\cdot$ Micro-level data $\cdot$ Population aging

JEL classification Q41 J J14 D D1

\section{Introduction}

Technologically and economically advanced economies have benefited enormously from using high-quality fossil fuels and monetary systems that promote forwardlooking business activities via large-scale transactions and speedy worldwide capital flows. However, it is crucial to recognize that none other than the double-edged nature of fossil fuel and money is now misdirecting those advanced nations. By double-edged nature, we mean to indicate that two related edges act in two distinct ways - one positively and one negatively. The double-edged nature of fossil fuel and money is an inseparable pair of driving wheels that have a crucial role in accelerating four formidable predicaments of aging populations [9]:

(1) The demographic predicament refers to shrinking population size and inverted population pyramids, associated with a high material standard of living, sufficient medical care, and prolonged education. Promotion of higher education accelerates later marriage, resulting in decreased fertility rates.

(2) The industrial structure predicament refers to a rapid industrial shift toward an increase in secondary and tertiary industries and a decrease in primary industry employment. Such shifts are usually accompanied by employee aging and the loss of long-term biophysical productivity and stability that is related to net primary production activity.

(3) The budget deficit predicament refers to the extensive issuance of public bonds to cope with persistent budget deficits, combined with heavy interest payments on those bonds.

(4) The social security predicament refers to the imminent collapse of social security systems due to a decreasing economically active population and sluggish GDP increase.

These four predicaments are closely related. However, this study focuses on how energy consumption patterns change over time; more specifically, changes in Japanese household energy consumption patterns are assumed to reflect the shrinking population and its inverted population pyramid in the aging population. Before framing the crucial dimensions associated with changes in Japan's household energy consumption patterns, Japan's demographic predicament will be briefly introduced.

Japan provides a striking example of the inevitable demographic predicament based on eight overarching factors: (1) a higher material standard of living; (2) reduction in labor hours; (3) promotion of higher education; (4) late marriage; (5) low fertility rate; (6) longer lifespan; (7) sufficient medical care provisions; and (8) a decent level of pension payments. In fact, between 1980 and 2010, the number of newborn babies in Japan significantly reduced, from about 1.58 million to 1.07 million (a 32\% decrease in 30 years). Furthermore, since around 2010, the Japanese population has been in steady decline. For example, the population size in 


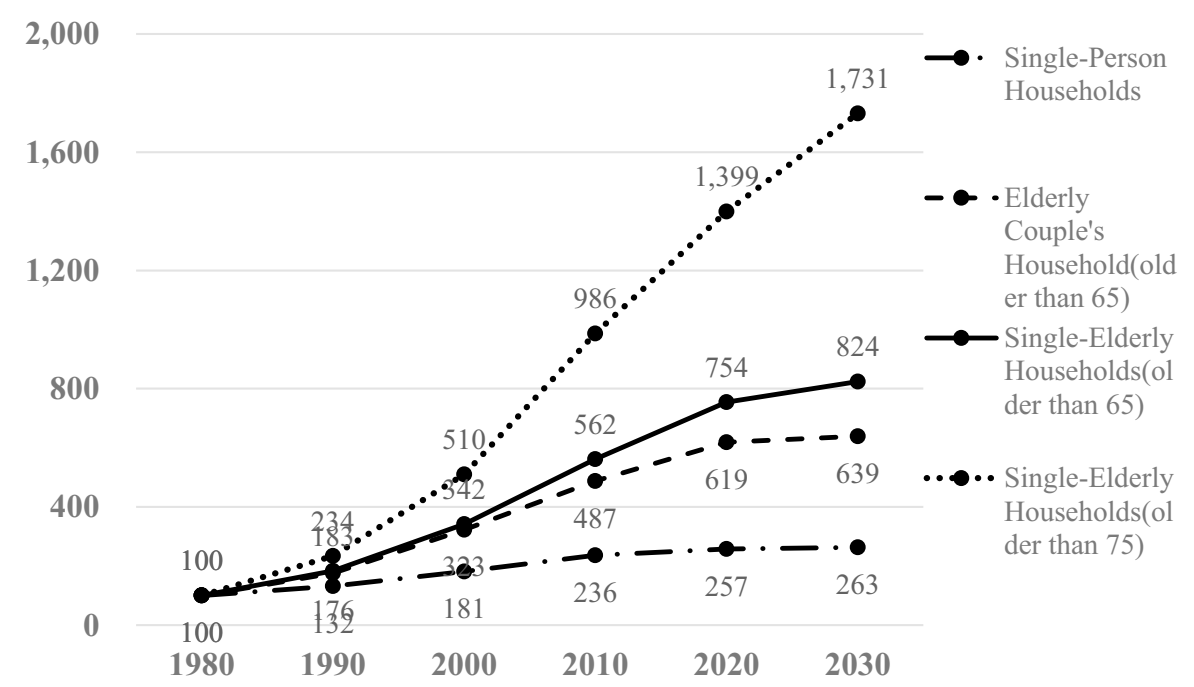

Fig. 1 Increasing number of elderly single-person households. Source: Ministry of Internal Affairs and Communications [12]

2010 was about 128 million. The National Institute of Population and Social Security Research (NIPSSR [15]) predicts that the Japanese population will fall to 90.2 million by 2060, a 30\% reduction from its 2010 level. While population size is an important driver of demographic challenges in any country, population structure is more crucial than population size in the case of Japan. The percentage of the Japanese population over 60 increased dramatically, from $12.9 \%$ in 1990 to $30.7 \%$ in 2010. The population of individuals over 75 years of age will likely increase, in relative terms, from $12.8 \%$ in 2016 to $25.7 \%$ in 2060 , even though the total population size will decrease by more than $29 \%$ compared to the 2016 level.

Although Japan is the example used in this study, aging and declining populations have become alarming in many developed societies. For instance, the European Union's population could decrease from 447.7 million in 2020 to 424.3 million in 2070 [4]. The elderly population ratio (the share of those aged 65 years or above) in the EU could increase from $20.6 \%$ in 2020 to $30.3 \%$ in 2070 [4].

The aging population of Japan has caused dramatic changes in household types as well as numbers. Figure 1 illustrates the relative changes in the number of four types of households, namely, single-person households, elderly couple households (inhabitants over 65 years of age), single-elderly households (over 65 years of age), and single-elderly households (over 75 years of age). It depicts these relative changes every 5 years, assigning the year 1980 a value of 100 . Relative changes are predicted up until 2030 (Ministry of Internal Affairs and Communications [12]). The first observation from this figure is that the relative size of single-elderly households over 75 has rapidly increased and could reach 1,731 in 2030.

In contrast, the relative number of all single households could reach 263 . Traditionally, most single-person households once consisted of young people who had moved from local areas to urban areas after either obtaining a job or having been 
given an independent residence from their parents following graduation from college. Nowadays, single-elderly households have become a sort of norm and represent the typical situation of the aging population in Japan.

Figure 1 suggests three crucial effects that provide the theoretical and empirical framework in which demographic changes properly explain changes in the household energy consumption patterns in Japan. These dimensions are (1) the pure aging effect, (2) the family structure effect, and (3) the cohort effect.

\section{Pure aging effect}

Elderly people stay home for a larger proportion of the day and usually require more heating and cooling comfort [2]. ${ }^{1}$ According to a survey by the Ministry of the Environment of Japan [10], the percentages of Japanese households reporting that "someone was at home almost every day during the daytime on weekdays" increased as household head age increased: 30\% (20-29), 42\% (30-39), 41\% (40-49), 47\% (50-59), 62\% (60-64), 77\% (65-74), and 87\% (75 or older). Matsumoto [8] compared winter energy usage between generations, reporting that elderly households consume more energy than younger households, even after controlling the usage time of heating equipment, household income, and housing sizes. The result strongly suggests that as people get older, they seek comfort at home and consequently use more energy.

\section{Family structure effect}

The average household size in Japan could shrink in an aging population. In particular, the relative number of single-person households might rise more rapidly, as suggested in Fig. 1. Subsequently, given a certain consumption level of energy, there must be an optimal size of households, compatible with the economy of scale, which can enjoy a certain acceptable level of comfort in terms of energy consumption.

Ironmongner et al. [6] examined the energy consumption of Australian households and identified significant economies of scale in household energy consumption. Based on the findings, they argue that smaller households suffer a double penalty in terms of greater per capita energy use and higher charge per unit of energy. Naturally, single-elderly households are the most penalized. Schröder et al. [17] analyzed Japanese households' panel data. They estimated that the 5\% decline in average household size between 2005 and 2010 caused an economy-wide loss in household economies of scale of nearly $4 \%$. Wu et al. [21] analyzed the panel data of Chinese households from 2010 to 2016 and confirmed substantial household scale economies in electricity consumption. They argue that incorporating scale effect into energy demand projections and sustainability assessments is crucial.

\footnotetext{
${ }^{1}$ In contrast, elderly people tend to go out for medical treatment; therefore, time spent for medical care might reduce energy consumption at home.
} 
These three studies suggest that relative household energy consumption does not necessarily decrease at the speed of population decline. A part of reduced energy consumption based on population decline will be lost due to "diseconomies of scale" that accompany population aging. Thus, the family structure effect must be incorporated into this theoretical model.

\section{Cohort effect}

People establish their lifestyles at a particular life stage and try to maintain them in their remaining life. Establishing particular tendencies based on past common experience can be termed as "hysteresis" [5]. During the establishment of a lifestyle, the socioeconomic conditions influence the daily practices in remaining life and may generate differences in energy consumption patterns between cohorts.

The number of traditional three-generation households with grandparents has drastically reduced with the aging population. Today, young people and married couples often live in households independently of their parents. Naturally, the number of homes increases, yet the size of new houses tends to become smaller. The Ministry of Land, Infrastructure, and Transport [13] survey found the average floor size of a new house decreased from $139.3 \mathrm{~m}^{2}$ in 2001 to $119.7 \mathrm{~m}^{2}$ in 2018. Smaller houses usually require less energy for space heating or lighting than larger houses; therefore, young generations living in smaller houses should consume less energy than old generations living in larger houses.

The types of energy used in a home vary from generation to generation. Over the last few decades, electrification has been promoted in many countries. As a result, households have reduced the use of kerosene and gas and increased electricity use, whereas elderly households living in old homes may still use kerosene for space heating. In contrast, younger households build homes that solely use electricity. Households using kerosene or gas should be replaced with those using electricity more intensively in the process of population aging. When assessing the effect of population aging on energy consumption, the changes in energy carrier types must be considered.

In sum, the demographic predicament might change energy consumption patterns in Japan due to the pure aging effect, the family structure effect, and the cohort effect. The energy expenditure data from the National Survey of Family Income and Expenditure (NSFE) in Japan (Statistics Bureau of Japan [18]) are presented below to investigate these three effects.

The remainder of this paper is structured as follows. The next section presents a brief review of the progress of population aging and the change in energy consumption in the sampling period. We explain our empirical methodology in the third section, and the results are reported in the fourth section. According to our estimation, household energy consumption increased by about $12 \%$ from 1995 to 2015 due to the pure aging effect, while it increased by about $16.6 \%$ from 1990 to 2015 due to the family structure effect. However, there are differences in energy usage intensity across generations, and younger generations consume less energy than older generations. The conclusion and policy implications are offered in the last section. 
(1,000 people)

(\%)

$1,29,000$

$1,28,000$

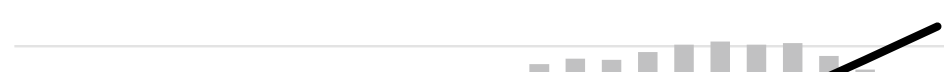

$1,27,000$

$1,26,000$

$1,25,000$

$1,24,000$

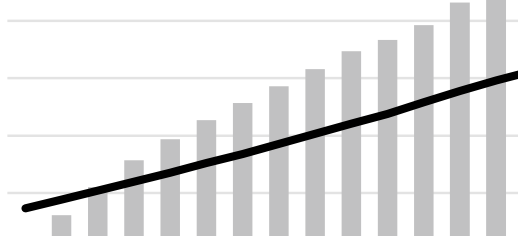

16.0

$1,23,000$

$1,22,000$

$1,21,000$

20.0

$1,20,000$

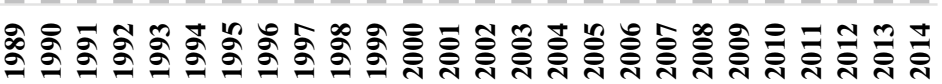

0.0

Fig. 2 Total population and aging rate (1989-2014). Source: Population Estimates, Census by the Ministry of Internal Affairs and Communications [12]

\section{Background information}

\section{Population aging}

Figure 2 presents the time-series change of Japan's total population from 1989 to 2014 , in addition to the percentage share of senior population equal to or older than 65 years, based on the data from Population Estimates and Census (the Ministry of Internal Affairs and Communications, [12]). The figure reveals that Japan's total population increased from 123 million in 1989 to 128 million in 2004. However, Fig. 2 indicates that the population size of Japan began decreasing more dramatically in the period between 2005 and 2010 .

The proportion of the senior population continued to increase from $11.6 \%$ in 1989 to $26.0 \%$ in 2014 . Japan is the exemplar of an aging population, with the highest aging rate globally, and the aging rate will increase further due to the eight previously mentioned causes of (1) a higher material standard of living; (2) reduction in labor hours; (3) promotion of higher education; (4) late marriage; (5) low fertility rate; (6) longer lifespan; (7) sufficient medical care provisions; and (8) a decent level of pension payments.

\section{Change in household energy consumption}

The NSFE is a nationwide cross-sectional survey initiated in 1959 that is conducted every 5 years. Each year, a survey of more than 50,000 households asks about their expenditure on energy carriers such as electricity, city gas, gasoline, kerosene, and propane gas used between September and November. Combining the expenditure 

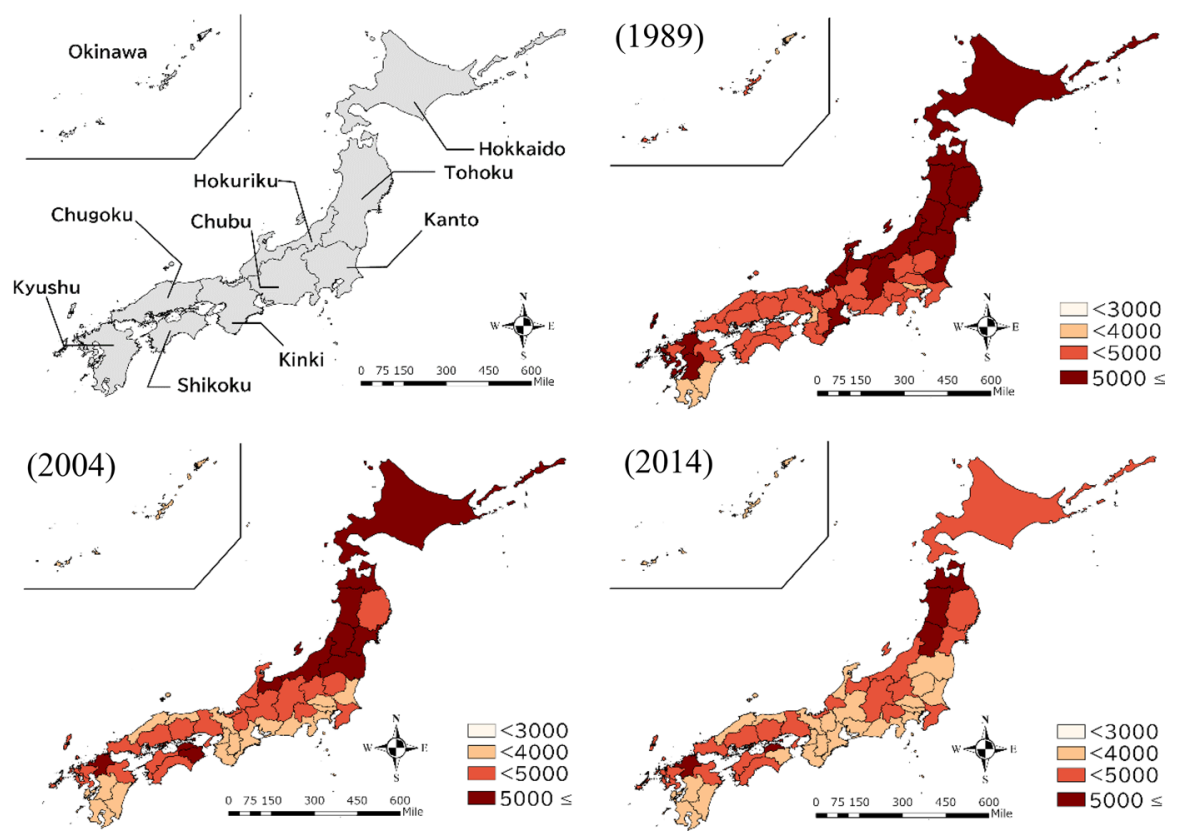

Fig. 3 Change in energy consumption of the average household (GJ/month) (excluding gasoline and diesel fuel consumption). Source: Estimated from the National Survey of Family Income and Expenditure (NSFE) in Japan (Statistics Bureau of Japan [18])

data with the energy price data from the Retail Price Survey (Statistics Bureau of Japan [19]), the consumption of each energy carrier was initially calculated. We then converted the estimated consumption of each energy carrier into gigajoules (GJ) based on the numerical table provided by the Ministry of the Environment of Japan [11].

The energy consumption of each household was divided by the number of household members to calcul ate the per capita monthly energy consumption. Although some households composed of multiple family members, the pattern of household energy consumption is assumed to be properly characterized by the household head information in the remaining analysis. For instance, if the household head is 42, a person in their early 40s would represent per capita energy consumption.

Figure 3 shows the change in households' average monthly energy consumption in each prefecture from 1989 to 2014. The figure demonstrates that average monthly energy consumption increased from 1989 to 1999 and decreased from 1999 to 2014. This result implies that Japanese households changed their energy-intensive lifestyle around the year 2000 . 


\section{Aging and cohort effects}

Using information about household head age, households were classified into the 12 cohort groups presented in Table 1 to compare the per capita energy consumption between the cohort groups.

The comparison of average energy consumption between cohorts in the same age group reveals unmistakable differences among generations. For instance, those in Cohort 11 belonging to the 55-59-year-old class in the 1999 survey year used on average $1033.06 \mathrm{GJ}$, a larger value than that of people who reached the 55-59-yearold class in later sampling years.

Figure 4 presents how the per capita energy consumption of each cohort changes with age. Per capita energy consumption shows a U-shaped relationship to age, decreasing in the $20 \mathrm{~s}$, minimizing in the $30 \mathrm{~s}$, and increasing after that. This appears to be the result of the tendency of active young people, who are normally in good physical shape, to spend more time outside of the residence, in relative terms, causing the per capita energy consumption of the cohort at home to become smaller.

\section{Change in household energy choice}

The higher aging rate has advanced more rapidly in certain parts of Japan, such as the Hokkaido, Shikoku, and Tohoku areas. There is also a tendency of population concentration in Tokyo metropolitan areas, thereby presenting a less rapid increase in the aging rate. Thus, regional energy consumption patterns reflecting these structural changes in regional populations are expected. Figures 3 and 5 are concerned with these regional differences in terms of energy consumption patterns.

Figure 3 shows how the total energy consumption of the average household changed from 1989 to 2014. In 1989, the energy consumption was very high in Hokkaido, Tohoku, and Hokuriku areas but low in major cities, including Tokyo and Osaka. In 2004, consumption decreased nationwide, but it significantly decreased in the Kansai area. Although this decreasing trend continued until 2014, total energy consumption remained high in Aomori, Iwate, and Yamagata in the Tohoku area, Kagawa in the Shikoku area, and Fukuoka in the Kyushu area. Perhaps because of the data collection period (September to November), energy consumption in colder areas, such as the Tohoku and Hokkaido areas, tended to be high.

Figure 5 shows how the electricity consumption of the average household changed from 1989 to 2014. This figure was derived by extracting only electricity consumption data from the total energy consumption data, demonstrating that electricity consumption increased during the sampling period. In 1989, electricity consumption in Chubu and Hokuriku areas was slightly higher than in other areas, but it was lower in Hokkaido. These geographical differences remained until 2014. The high electricity consumption in the Hokuriku region is assumed to be because hydroelectric power generation is used, and the price of electricity is relatively lower. Low electricity consumption in the Hokkaido area is assumed to be related to a considerable amount of kerosene used for space heating in winter. 


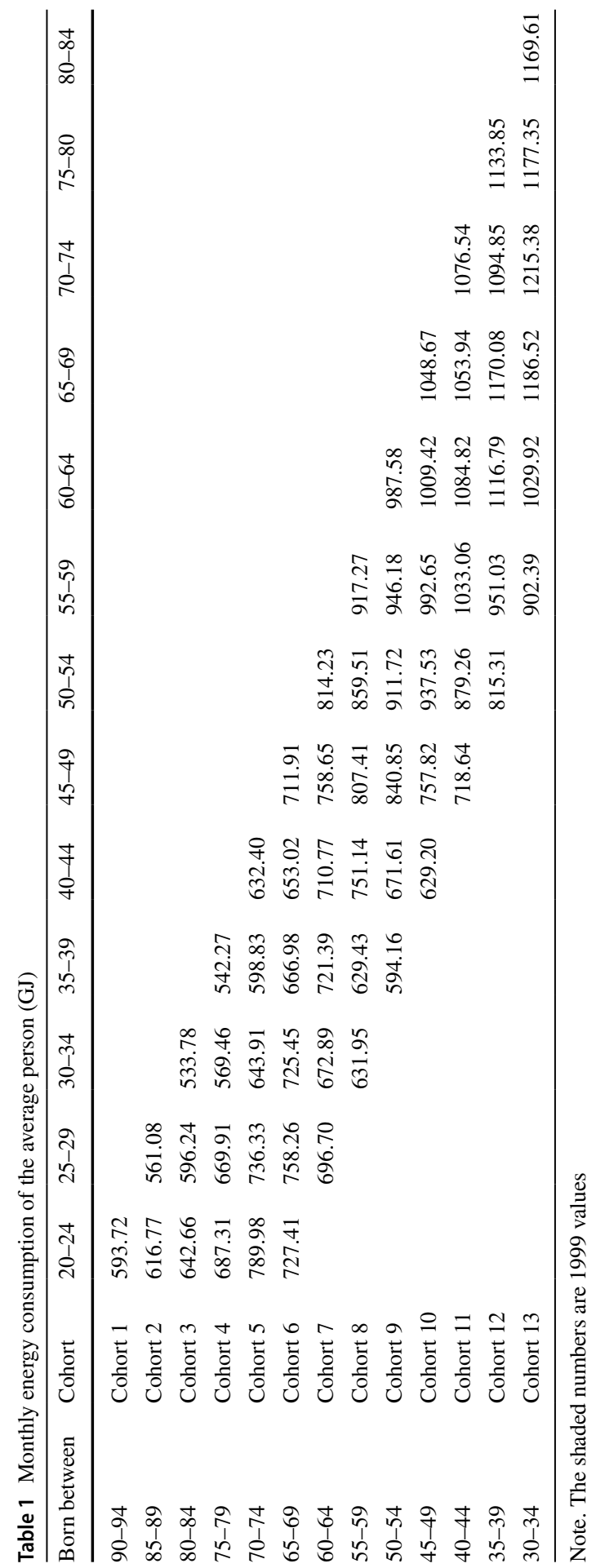




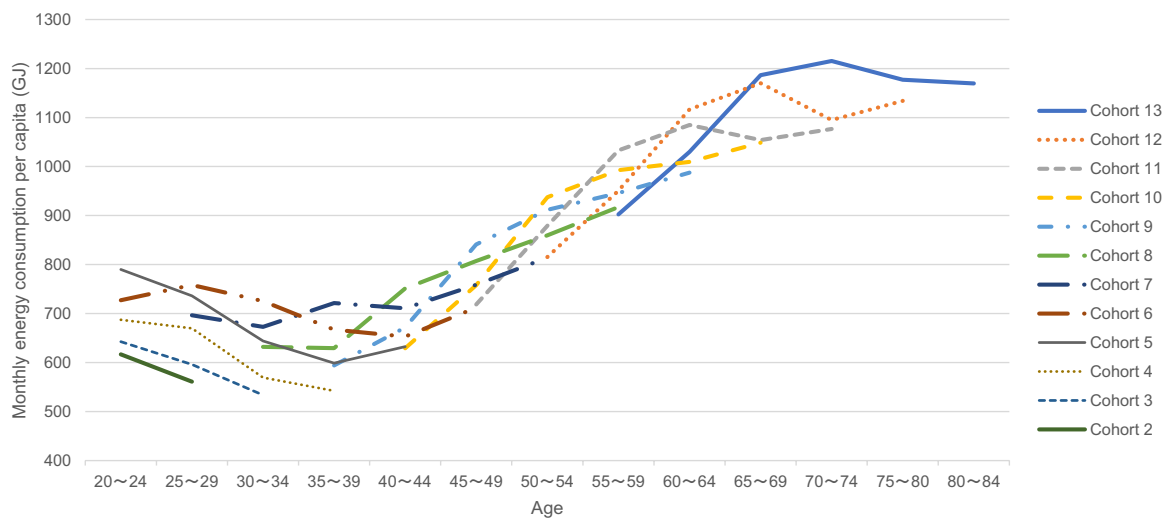

Fig. 4 Comparison of energy consumption between generational cohorts. Source: The National Survey of Family Income and Expenditure (NSFE) in Japa n (Statistics Bureau of Japan [18])
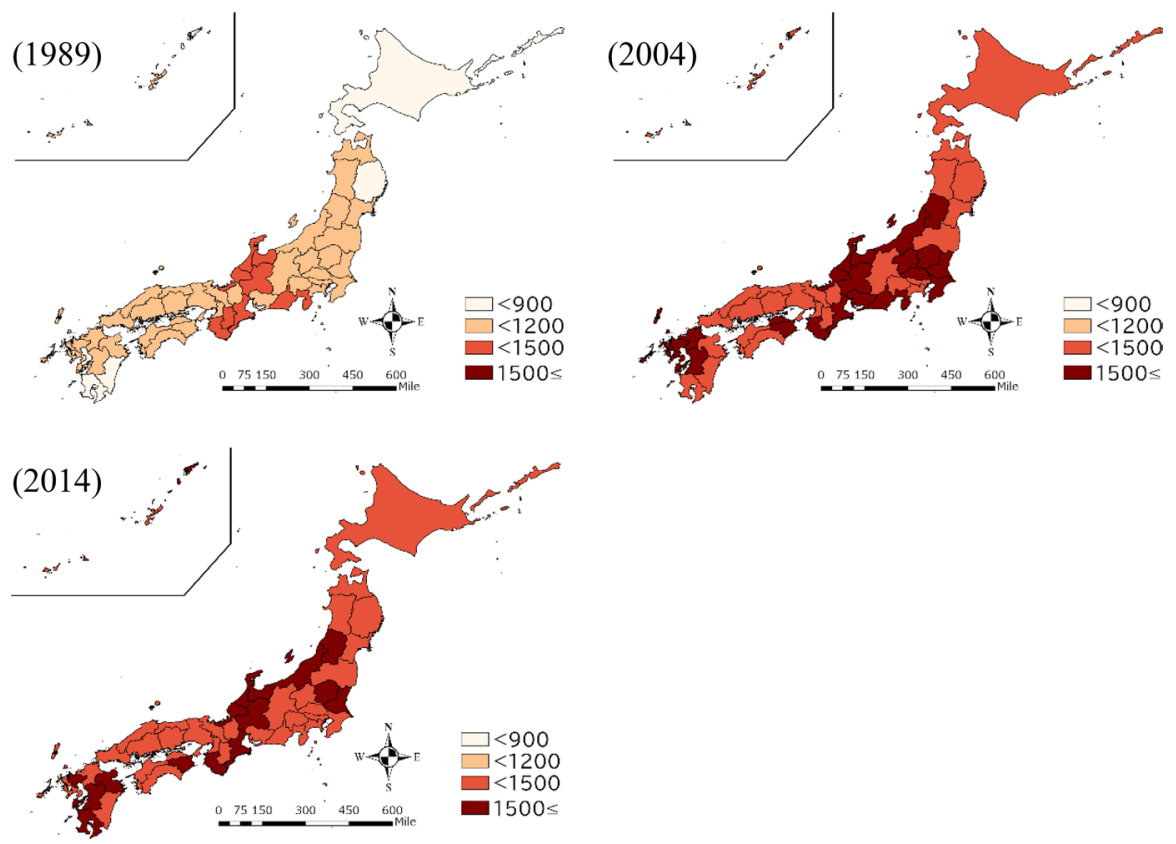

Fig. 5 Change in electricity consumption of the average household (GJ/month). Source: Estimated from the National Survey of Family Income and Expenditure (NSFE) in Japan (Statistics Bureau of Japan [18])

Electricity consumption increased nationwide from 1989 to 2004 but decreased in several prefectures from 2004 to 2014. The above analysis suggests that electrification progressed in the 1990s, the consumption of gas and kerosene decreased, and electricity consumption reached a peak around the year 2000 . 


\section{Empirical model}

This study aims to examine how population aging affects household energy consumption, decomposing the effect into three components of the pure aging effect, the family structure effect, and the cohort effect.

Using the previously defined data on per capita monthly energy consumption, a median person was identified from those in their late 30s in the 1989 survey year. This representative person was selected from a member of a three-person household living in Osaka Prefecture. The household earned JPY 5.2 million and consumed 503.96 GJ of energy in 1989. Although both electricity and city gas were used, kerosene was not used in this median household. The following analysis compares energy consumption between remaining households and this median household to examine whether age and cohort differences can explain different energy consumption patterns:

$$
\begin{aligned}
\ln \left(\frac{E_{i}}{E^{*}}\right)= & \sum_{a=1}^{6} \beta_{a} D_{i, a}+\sum_{c=1}^{12} \beta_{c} D_{i, c}+\sum_{t=1}^{7} \beta_{t} D_{i, t}+\sum_{y=1}^{5} \beta_{y} D_{i, y}+\beta_{\text {Inc }} \ln \left(\frac{\operatorname{Inc} c_{i}}{\operatorname{Inc} c^{*}}\right) \\
& +\beta_{\text {Temp }} \ln \left(\frac{\text { Temp }_{i}}{\text { Temp }^{*}}\right)+\sum_{p=1}^{46} \beta_{p} D_{i, p}+\varepsilon_{i}
\end{aligned}
$$

The dependent variable on the left-hand side represents the logarithm rate of change in per capita total energy or electricity consumption. On the right-hand side, $D_{i, a}$ are age dummies, $D_{i, c}$ are cohort dummies, and $D_{i, t}$ are household-type dummies.

"Pure aging effects" are measured by the parameter $\beta_{a}$, assumed to be constant throughout the sampling year and between different cohorts. People in different cohorts may use energy in diverse ways because the size of their houses is different, or they use diverse types of energies. "Cohort effects" are measured by $\beta_{c}$, assumed to be constant throughout the sampling year.

We classified households into eight types: single-person households; senior single-person households; couple-only households; couple and children households; single-parent households; households living with parents; three-generation households; and other households. The family structure effect is evaluated by the parameter $\beta_{t}$. The comparison of these parameters enables the quantific ation of "economies of scale" in household energy consumption.

Several control variables for improving the estimation are included. As seen in the previous section, Japanese households experienced a turning point in energy consumption around the year 2000. To evaluate the difference between the survey years, year dummies $D_{i, y}$ are included.

Previous studies reported that energy consumption increases with a rise in income. We include the logarithm rate of change in household energy consumption as a control variable. The parameter $\beta_{\text {Inc }}$ evaluates the per capita income elasticity of energy consumption.

The average temperature is also included as a control variable. Past temperature data were obtained from the Japan Meteorological Agency [7] and checked against the location of each household to calculate the average temperature for the three survey months of September, October, and November. Since the survey months for single-person 
households are September and October, we calculated the average temperature for the two months. Finally, prefecture dummies are included in the model to assess the differences between prefectures. The error term $\varepsilon_{i}$ is assumed to be distributed i.i.d. normal.

\section{Empirical results}

\section{Income elasticity}

The estimation result of Eq. 1 is presented in Table 2. According to our estimation, the income elasticity of total energy demand is 0.110 on a per capita basis, while that of electrical energy demand is 0.135 ; therefore, the income elasticity of electricity demand is higher than that of total energy.

Although the income elasticity of residential energy demand has been estimated in many studies, it is often evaluated on a household basis. Since income elasticity is estimated on a per capita basis in this study, the number of persons in the household needs to be multiplied to compare the result with previous studies. Based on the calculation, the income elasticity of total energy demand was 0.363 on a household basis, while that of electricity demand was 0.445 .

Csereklyei [3] analyzed the data of residential electricity demand in European Union countries between 1996 and 2016 and estimated the long-run income elasticity of electricity demand at around 0.61 . Pellini [16] conducted a comprehensive literature review and reported that the long-run income elasticity of electricity demand ranged from 0.33 to 1.96 in previous studies. The income elasticity of demand estimated in this paper is slightly lower than that found in previous studies.

\section{Temperature elasticity}

In this study, the temperature elasticity of total energy demand is estimated at -0.361 , while that of electricity demand is -0.158 . This result suggests that gas and kerosene demand is much more temperature-sensitive than electricity demand.

The result also suggests that people living in colder regions require more energy for space heating since the sampling months are September, October, and November, as a significant difference between warm and cold regions is revealed. According to our estimation, people in the coldest area (Asahikawa city) require $16.77 \%$ more energy than those in the base area (Hirakata city). In contrast, people in the warmest area (Yonaguni Island) require $20.18 \%$ less energy.

\section{Pure aging effect}

Figure 6 shows that per capita energy consumption increases with age. Senior citizens over 75 use $50 \%$ more energy than young people in their early 20 s. As noted previously, this is because seniors tend to stay home more and maintain a higher room temperature. 
Table 2 Determinants of residential energy consumption $(N=295,220)$

\begin{tabular}{|c|c|c|c|c|c|c|}
\hline \multirow[b]{2}{*}{ Variable } & \multicolumn{3}{|c|}{ Total energy consumption } & \multicolumn{3}{|c|}{ Electricity consumption } \\
\hline & Coefficient & St. error & Change & Coefficient & St. error & Change \\
\hline & $\beta$ & & $\pi$ & $\beta$ & & $\pi$ \\
\hline \multicolumn{7}{|l|}{ Control variables } \\
\hline Income & $0.111^{* * *}$ & 0.002 & & $0.135^{* * *}$ & 0.002 & \\
\hline Temperature & $-0.361^{* * *}$ & 0.051 & & $-0.158^{* * *}$ & 0.030 & \\
\hline \multicolumn{7}{|c|}{ Pure aging effects (base $=$ late $30 \mathrm{~s}$ ) } \\
\hline Early 20 s & $-0.122^{* * *}$ & 0.017 & $-11.5 \%$ & $-0.116^{* * *}$ & 0.013 & $-10.9 \%$ \\
\hline Late 20 s & $0.015^{* *}$ & 0.007 & $1.6 \%$ & $-0.025^{* * *}$ & 0.006 & $-2.4 \%$ \\
\hline Early 30 s & $0.020^{* * * *}$ & 0.005 & $2.1 \%$ & $-0.008^{* *}$ & 0.004 & $-0.8 \%$ \\
\hline Early 40 s & $0.048^{* * *}$ & 0.004 & $4.9 \%$ & $0.062^{* * *}$ & 0.003 & $6.4 \%$ \\
\hline Late $40 \mathrm{~s}$ & $0.143^{* * *}$ & 0.004 & $15.4 \%$ & $0.156^{* * *}$ & 0.004 & $16.9 \%$ \\
\hline Early 50s & $0.215^{* * *}$ & 0.005 & $24.0 \%$ & $0.233^{* * *}$ & 0.004 & $26.2 \%$ \\
\hline Late $50 \mathrm{~s}$ & $0.255^{* * *}$ & 0.006 & $29.0 \%$ & $0.273^{* * *}$ & 0.005 & $31.3 \%$ \\
\hline Early $60 \mathrm{~s}$ & $0.298^{* * *}$ & 0.007 & $34.7 \%$ & $0.321^{* * *}$ & 0.005 & $37.8 \%$ \\
\hline Late $60 \mathrm{~s}$ & $0.299^{* * *}$ & 0.008 & $34.8 \%$ & $0.312^{* * *}$ & 0.006 & $36.6 \%$ \\
\hline Early 70s & $0.301^{* * *}$ & 0.009 & $35.1 \%$ & $0.306^{* * *}$ & 0.007 & $35.8 \%$ \\
\hline Late $70 \mathrm{~s}$ & $0.319^{* * * *}$ & 0.010 & $37.6 \%$ & $0.311^{* * * *}$ & 0.008 & $36.4 \%$ \\
\hline Early 80 s & $0.336^{* * * *}$ & 0.014 & $39.9 \%$ & $0.321^{* * * *}$ & 0.011 & $37.8 \%$ \\
\hline \multicolumn{7}{|c|}{ Cohort effects $($ base $=$ Cohort 9 , late 30 s in 1989) } \\
\hline Cohort 1 & -0.057 & 0.049 & $-5.6 \%$ & -0.017 & 0.047 & $-1.7 \%$ \\
\hline Cohort 2 & $-0.198^{* * *}$ & 0.019 & $-17.9 \%$ & $-0.104^{* * *}$ & 0.016 & $-9.9 \%$ \\
\hline Cohort 3 & $-0.208^{* * *}$ & 0.013 & $-18.8 \%$ & $-0.084^{* * *}$ & 0.011 & $-8.0 \%$ \\
\hline Cohort 4 & $-0.183^{* * * *}$ & 0.009 & $-16.7 \%$ & $-0.044^{* * *}$ & 0.008 & $-4.3 \%$ \\
\hline Cohort 5 & $-0.105^{* * *}$ & 0.008 & $-10.0 \%$ & -0.003 & 0.006 & $-0.3 \%$ \\
\hline Cohort 6 & $-0.047^{* * *}$ & 0.006 & $-4.5 \%$ & $0.013^{* * * *}$ & 0.005 & $1.4 \%$ \\
\hline Cohort 7 & $-0.014^{* * *}$ & 0.005 & $-1.4 \%$ & $0.010^{* *}$ & 0.004 & $1.0 \%$ \\
\hline Cohort 8 & -0.004 & 0.004 & $-0.4 \%$ & -0.001 & 0.003 & $-0.1 \%$ \\
\hline Cohort 10 & -0.003 & 0.003 & $-0.3 \%$ & 0.004 & 0.003 & $0.4 \%$ \\
\hline Cohort 11 & $0.009^{* *}$ & 0.004 & $0.9 \%$ & $0.014^{* * *}$ & 0.003 & $1.4 \%$ \\
\hline Cohort 12 & -0.001 & 0.004 & $-0.1 \%$ & $0.008^{* *}$ & 0.003 & $0.8 \%$ \\
\hline \multicolumn{7}{|c|}{ Household type (base $=$ couple and children) } \\
\hline Couple only & $0.340^{* * *}$ & 0.003 & $40.6 \%$ & $0.374^{* * *}$ & 0.002 & $45.3 \%$ \\
\hline Single parent & $0.249^{* * *}$ & 0.005 & $28.3 \%$ & $0.254^{* * *}$ & 0.004 & $29.0 \%$ \\
\hline Couple and parents & $0.106^{* * *}$ & 0.006 & $11.2 \%$ & $0.190^{* * *}$ & 0.004 & $20.9 \%$ \\
\hline Three generation & $-0.158^{* * *}$ & 0.004 & $-14.6 \%$ & $-0.052^{* * *}$ & 0.003 & $-5.0 \%$ \\
\hline Other & $-0.022^{* * *}$ & 0.005 & $-2.2 \%$ & $0.065^{* * *}$ & 0.004 & $6.7 \%$ \\
\hline Single elderly & $0.604^{* * *}$ & 0.012 & $82.9 \%$ & $0.665^{* * *}$ & 0.008 & $94.4 \%$ \\
\hline Single & $0.401^{* * * *}$ & 0.011 & $49.4 \%$ & $0.535^{* * *}$ & 0.008 & $70.8 \%$ \\
\hline \multicolumn{7}{|c|}{ Survey year $($ base $=1989)$} \\
\hline 1994 & $0.135^{* * *}$ & 0.005 & $14.5 \%$ & $0.305^{* * *}$ & 0.004 & $35.6 \%$ \\
\hline 1999 & $0.199^{* * *}$ & 0.006 & $22.1 \%$ & $0.360^{* * *}$ & 0.004 & $43.4 \%$ \\
\hline 2004 & $0.196^{* * * *}$ & 0.006 & $21.6 \%$ & $0.424^{* * *}$ & 0.004 & $52.8 \%$ \\
\hline 2009 & $0.122^{* * *}$ & 0.006 & $13.0 \%$ & $0.366^{* * *}$ & 0.005 & $44.2 \%$ \\
\hline 2014 & $0.108^{* * *}$ & 0.007 & $11.4 \%$ & $0.414^{* * *}$ & 0.005 & $51.3 \%$ \\
\hline $\mathrm{R}^{2}$ & 0.409 & & & 0.745 & & \\
\hline
\end{tabular}


Table 2 (continued)

Prefecture dummies are included, and robust standard errors are used in the estimation.

*** and ${ }^{* *}$ indicate statistically significant at $1 \%$ and $5 \%$, respectively
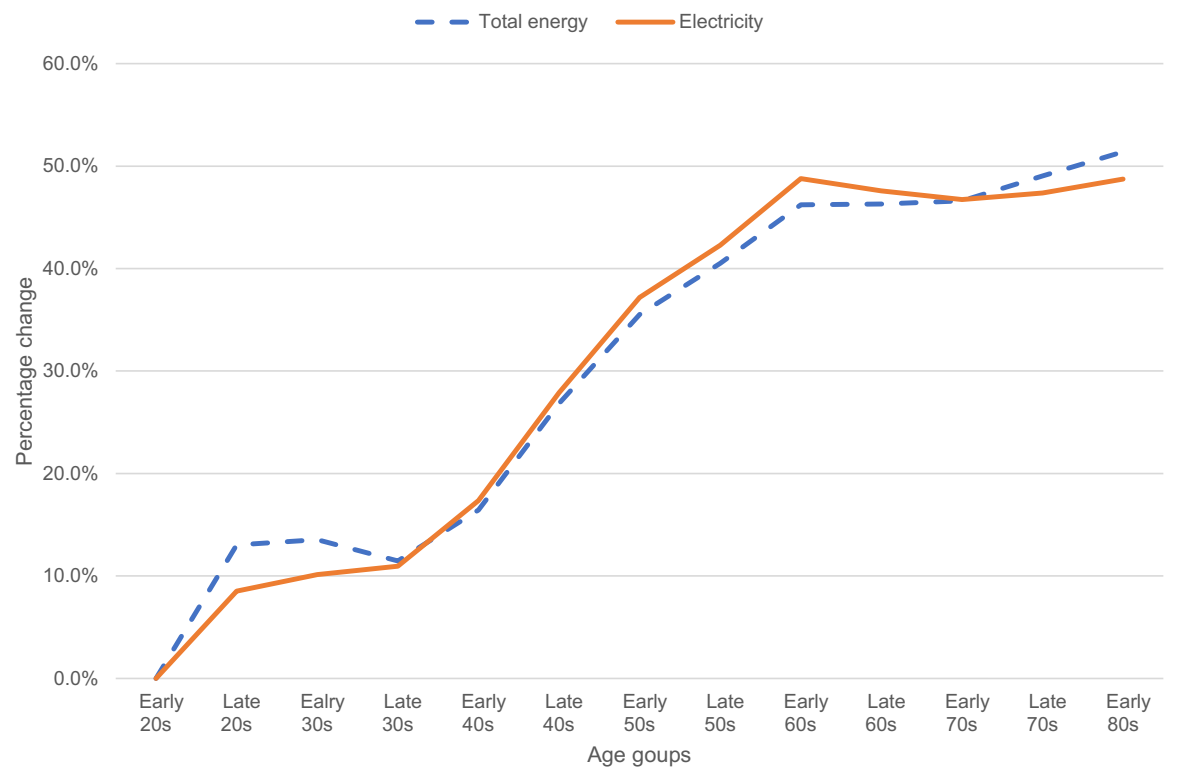

Fig. 6 Pure aging effects. Source: Authors' estimation

Combining aging effect information with demographic data (NIPSSR [14]; Statistics Bureau of Japan [20]) enables an assessment of the pure aging effect on household energy consumption.

The share of households is defined as $n$ persons within age group $a$ in the base year by $s_{a, n}^{0}{ }^{2}$ using 1994 as the base year due to the data limitations. If the change in the share of age group $a$ is defined among all age groups by $\Delta s_{a}^{y}$, then the pure aging effect is defined as $\varsigma_{a}=\sum_{n=1}\left(\pi_{a} s_{a, n}^{0} n\right) \Delta s_{a}^{y}$. Here, $\pi_{a}$ is the percentage difference in energy consumption between age groups presented in Table 2 .

The average number of individuals in each age group has changed during the sampling period. However, to focus on the pure aging effect induced by the age change, the average number of persons in each age group is maintained at $s_{a, n}^{0}$ in this analysis.

The results reveal that the pure aging effect on total energy consumption was $12.3 \%$ from 1994 to 2014, while electricity consumption was $11.8 \% .^{3}$ This result suggests

\footnotetext{
2 The data from Vital Household Statistics by NIPSSR were matched with the following year's census data by Statistics Bureau of Japan.

${ }^{3}$ Households with heads below 20 years of age or over 85 are not included in this simulation.
} 
that the increase in the proportion of elderly people raised household energy consumption by more than $10 \%$ from 1994 to 2014 . As residential electricity consumption has only decreased by 19.29\% from 2005 (the peak year) to 2018 (Agency for Natural Resources and Energy [1]), the pure aging effect appears to be remarkably sizable.

\section{Cohort effect}

Cohort 9, born between 1950 and 1954, is chosen as the base cohort for the comparison of energy consumption between the 13 cohorts defined in Table 2. The estimation result demonstrates that younger generations use less energy than older generations. For instance, the generation born between 1975 and 1980 uses 16.7\% less energy than those born between 1950 and 1954. This is assumed to result from younger generations living in smaller houses and engaging in energy-saving lifestyles. Thus, energy conservation should be more attainable as generations change.

Cohort difference becomes less clear in the case of electricity consumption. Indeed, the generation born in the 1960s consumes more electricity than the generation born between 1950 and 1954. Perhaps this result is because older generations use more gas and kerosene than younger generations.

\section{Family structure effect}

Table 2 also shows how energy consumption differs by household type. The result unquestionably indicates the presence of economies of scale. The per capita energy consumption of single-elderly households is larger than that of households composed of parents and children by $82.9 \%$. In contrast, the per capita energy consumption of three-generation households is smaller by $14.6 \%$.

Economies of scale accompanied with population aging are calculated by combining the estimation results with census data. The share of household type $t$ in the base year and the compared year are, respectively, represented by $s_{t}^{0}$ and $s_{t}^{y}$. The average number of persons of household type $t$ in the base year and the compared year are $\bar{n}_{t}^{0}$ and $\bar{n}_{t}^{y}$, respectively. The family structure effect is then measured by $\varsigma_{t}=\sum_{t=1}^{7}\left(\pi_{t} \bar{n}_{t}^{y} s_{t}^{y}-\pi_{t} \bar{n}_{t}^{0} s_{t}^{0}\right)$, where $\pi_{t}$ is the percentage difference in energy consumption between the distinct household types, as shown in Table 2. Family size decreased during the sampling year. The share of couples and children households decreased from $37.3 \%$ in 1990 to $26.9 \%$ in 2015 . In contrast, the share of single-person households increased from $23.1 \%$ to $34.6 \%$. According to our calculation, household energy consumption increased by $16.6 \%$ due to family structure change from 1990 to 2015.

\section{Conclusion and policy implications}

This study examined how population aging affects household energy consumption based on an analysis of micro-level energy consumption data of Japanese households from 1989 to 2014, measuring the pure aging effect, the cohort effect, and 
the family structure effect. The results confirm that energy consumption increases by about $12 \%$ due to the pure aging effect. Furthermore, population aging changes households' composition and reduces the size of households. Due to this downsizing, household energy consumption increased by about $16.6 \%$. These estimations suggest that household energy consumption increased significantly with population aging during the sampling period.

Different generations have diverse lifestyles and use energy differently. The cohort comparison in this study reveals that younger generations consume less energy than older generations. This is assumed to be because the former live in smaller houses and practice more energy-efficient approaches. Through generational change, these improvements in energy efficiency partially offset the increase in energy consumption caused by population aging.

Although this study evaluated the effect of an aging population on household consumption at a national level, the effect of population aging varies widely between regions. While the population is aging much faster in rural areas than urban areas, it is difficult to expect energy efficiency improvement through generational change. Therefore, the increase in energy consumption through population aging is likely more pronounced in rural areas. Policymakers must consider managing increases in energy consumption due to population aging in rural areas, as young people are moving from rural areas to cities and rural economies are shrinking.

In earlier stages of economic development, people significantly shifted traditional household activities to rely on the marketplace, where new economic activities began to influence every aspect of life. Consequently, individuals' relative allocation of time was altered in terms of market transactions (i.e., purchasing a considerable portion of previously homemade life necessities). However, at the more advanced stage of economic development, and particularly in an aging society, how time allocation patterns will change over time remains unknown. In fact, with an aging population such as Japan, many people now purchase various goods through internet transactions without going out shopping. Furthermore, a multitude of meal delivery services has become available in recent years. New medical care services through internet consultancy with doctors via telemedicine have also increased because of the Covid-19 pandemic. Elderly people will continue to use such medical services intensively in the future. All the changes identified in this study strongly suggest that more intensive use of electricity per capita is necessary to accommodate the lifestyle changes described. Whether a smooth global shift to a higher share of electricity production through renewable energy can be achieved is really a moot point for the aging society. New and disruptive energy technology is desperately needed.

Acknowledgements This study was conducted with financial support from Aoyama Gakuin University Research Institute.

\section{Declarations}

Conflict of interest The authors declare that they have no known competing financial interests or personal relationships that could have influenced the work reported in this paper. 


\section{References}

1. Agency for Natural Resources and Energy. 2020. Energy White Paper. https://www.enecho.meti.go. jp/about/whitepaper/ accessed 2021.06.30.

2. Bardazzi, R., \& Pazienza, M. G. (2017). Switch off the light, please! Energy use, aging population and consumption habits. Energy Economics, 65, 161-171. https://doi.org/10.1016/j.eneco.2017.04. 025

3. Csereklyei, Z. (2020). Price and income elasticities of residential and industrial electricity demand in the European Union. Energy Policy, 137(2020), 111079. https://doi.org/10.1016/j.enpol.2019. 111079

4. Eurostat. 2020. The EU's population projected up to 2100. https://ec.europa.eu/eurostat/web/produ cts-eurostat-news/-/DDN-20190710-1. accessed 2021.06.06.

5. Georgescu-Roegen, N. (1971). The Entropy Law and the Economics Process. Harvard University Press.

6. Ironmonger, D. S., Aitken, C. K., \& Erabas, B. (1995). Economies of scale in energy use in adultonly households. Energy Economics, 17(4), 301-301. https://doi.org/10.1016/0140-9883(95) 00032-P

7. Japan Meteorological Agency. 2021. Past weather data.https://www.data.jma.go.jp/obd/stats/etrn/ index.php. Accessed 2021.03.15.

8. Matsumoto, S. (2020). Time allocation and environmental burden of households. Review of environmental economics and policy studies, 13(2), 31-43. https://doi.org/10.14927/reeps.13.2_31

9. Mayumi, K. T. (2020). Sustainable Energy and Economics in an Aging population: Lessons from Japan. Springer.

10. Ministry of the Environment of Japan. 2015. Household $\mathrm{CO}_{2}$ Statistics. http://www.env.go.jp/earth/ ondanka/ghg/kateiCO2tokei.html accessed 2021.06.10.

11. Ministry of the Environment of Japan. 2020. Survey on the Actual Conditions of Carbon Dioxide Emissions from Residential Sector. https://www.env.go.jp/earth/ondanka/ghg/kateitokei/chosa05. pdf accessed 2021.07.20.

12. Ministry of Internal Affairs and Communications. 2021. http://www.soumu.go.jp/ accessed 2021.06.10.

13. Ministry of Land, Infrastructure, and Transport. 2021. Housing stock condition in Japan. https:// www.mlit.go.jp/policy/shingikai/content/001323208.pdf. Accessed 10 June 2020.

14. National Institute of Population and Social Security Research. 1989-2014. The National Survey on Household Changes. http://www.ipss.go.jp/site-ad/index_Japanese/ps-dotai-index.html accessed 2020.06.08.

15. National Institute of Population and Social Security Research. 2017. Population Projections for Japan: 2016-2065, With long-range Population Projections: 2066-2115. http://www.ipss.go.jp/ppzenkoku/j/zenkoku2017/pp29suppl_reportALL.pdf. Accessed 10 June 2021.

16. Pellini, E. (2021). Estimating income and price elasticities of residential electricity demand with Autometrics. Energy Economics, forthcoming. https://doi.org/10.1016/j.eneco.2021.105411

17. Schröder, C., Rehdanz, K., Narita, K., \& Okubo, T. (2015). The decline in average family size and its implications for the average benefits of within-household sharing. Oxford Economic Papers, 67(3), 760-780. https://doi.org/10.1093/oep/gpv033

18. Statistics Bureau of Japan. 1989-2014a. National Survey of Family Income and Expenditure. https:// www.stat.go.jp/data/zensho/2014/index.html. accessed 2021.06.10.

19. Statistics Bureau of Japan. 1989-2014b. Retail Price Survey. https://www.stat.go.jp/data/kouri/ index.html accessed 2021.06.10.

20. Statistics Bureau of Japan. 1990-2015. Population Census. https://www.stat.go.jp/english/data/ kokusei/index.html accessed 2021.06.10.

21. Wu, W., Kanamori, Y., Zhang, R., Zhou, Q., Takahashi, K., \& Masui, T. (2021). Implications of declining household economies of scale on electricity consumption and sustainability in China. Ecological Economics. https://doi.org/10.1016/j.ecolecon.2021.106981

Publisher's Note Springer Nature remains neutral with regard to jurisdictional claims in published maps and institutional affiliations. 